\title{
Copper-Mediated Cascade Synthesis of Open-Cage Fullerenes
}

\author{
Michio Yamada, ${ }^{* \dagger}$ Asumi Ishitsuka, ${ }^{\dagger}$ Yutaka Maeda, ${ }^{\dagger}$ Mitsuaki Suzuki, ${ }^{\ddagger}$ and Hiroyasu Sato ${ }^{\S}$ \\ ${ }^{\dagger}$ Department of Chemistry, Tokyo Gakugei University, Koganei, Tokyo 184-8501, Japan \\ ${ }^{\ddagger}$ Department of Chemistry, Josai University, Sakado, Saitama 350-0295, Japan \\ ${ }^{\S}$ Rigaku Corporation, Akishima, Tokyo 196-8666, Japan \\ Supporting Information Placeholder
}

\begin{abstract}
An open-cage fullerene bearing an eight-membered ring orifice has been synthesized in one pot by the reaction of $\mathrm{C}_{60}$ with propargylic phosphate in the presence of $\mathrm{CuCl}$. The reaction cascade involves the transformation of the phosphate to the 1,3-dienyl phosphate, which enables the reaction with $\mathrm{C}_{60}$ by $[4$ +2 ] cycloaddition to form the cyclohexene-annulated intermediate, and subsequent intramolecular syn-elimination of the phosphodiester affords the cyclohexadiene-annulated fullerene derivative as the precursor for the open-cage fullerene.
\end{abstract}

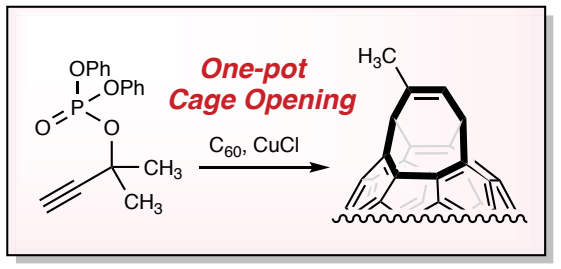

Open-cage fullerenes have been attracted special interest for their ability to serve as scaffolds for building molecular containers for host-guest chemistry, and also as precursors for endohedral fullerenes that encage small atom(s) or molecule(s). ${ }^{1}$ Recent studies have also shown that open-cage fullerenes are applicable for electron-accepting materials in organic photovoltaic devices. ${ }^{2}$ The preparation of open-cage bisfulleroids bearing an eightmembered ring orifice via formation of cyclohexadiene-annulated fullerene derivatives (cyclohexadienofullerenes) followed by photochemical $[4+4]$ and subsequent retro-[2 $+2+2]$ cycloaddition sequence is regarded as a highly reliable approach among the reported cage-opening reactions. ${ }^{3-7}$ Furthermore, the enlargement of the eight-membered ring orifice of the bisfulleroid to a 12-membered one is feasible via photo-oxygenation with singlet oxygen. ${ }^{8}$ Further orifice-enlargement is also possible through additional reactions, such as sulfur insertion and the reactions with hydrazones, ${ }^{9}$ which furnish open-cage fullerenes possessing large orifices suitable for encapsulating small molecules. $^{10}$ In this scenario, the preparation of endohedral fullerenes can be achieved by subsequent orifice-closing reactions. To date, organic syntheses of $\mathrm{H}_{2} @ \mathrm{C}_{60}{ }^{11}$, $\mathrm{H}_{2} \mathrm{O} @ \mathrm{C}_{60}{ }^{12} \mathrm{HF} @ \mathrm{C}_{60}{ }^{13}$ and $\mathrm{CH}_{4} @ \mathrm{C}_{60}{ }^{14}$ from $\mathrm{C}_{60}$ have been accomplished through the formation of such bisfulleroids and their dioxygenated intermediates."

Nevertheless, the synthetic methodologies which allow access to cyclohexadienofullerenes and their analogues are limited, which is the key bottleneck in the development of applications in this area. In addition, most of them are rely on the use of tethered diynes, ${ }^{4}$ pyridazines, ${ }^{5}$ or palladacyclopentadienes, ${ }^{6}$ which shows the limited substrate scope of these approaches. In this context, the exploration of efficient approaches for the synthesis of cyclohexadienofullerenes and bisfulleroids is in great demand for developing a variety of open-cage and endohedral fullerenes. We recently demonstrated formal $[2+2]$ and $[4+2]$ cycloadditions between $\mathrm{C}_{60}$ and propargylic esters under transitionmetal catalysis. ${ }^{15}$ During this study, we encountered an unprecedented formation of cyclohexadienofullerene and bisfulleoid via a one-pot $\mathrm{CuCl}$-mediated reaction of $\mathrm{C}_{60}$ with the easily accessible propargylic phosphate, which is depicted in Scheme 1.

The typical procedure for the reaction comprised mixing $\mathrm{C}_{60}$ and propargylic phosphate 1 in 1,2-dichlorobenzene (1,2-DCB), and its treatment with $\mathrm{CuCl}$ at elevated temperatures under an argon atmosphere. The purification and isolation were accomplished by preparative HPLC to afford the brown-colored cyclohexadienofullerene $\mathbf{2}$, the browncolored alkylidenecyclohexene-annulated fullerene $\mathbf{3}$, and the purple-colored open-cage bisfulleroid 4 (see Table 1 ). While the reactions did not proceed at $80^{\circ} \mathrm{C}$, they proceeded smoothly at above $110{ }^{\circ} \mathrm{C}$ and yielded the derivatives in reasonable yields. Under dark conditions, the thermal reaction of $\mathrm{C}_{60}$ with 1 at $110{ }^{\circ} \mathrm{C}$ for $24 \mathrm{~h}$ afforded 2 as the major product, along with 3 and 4 as the minor products (entry 1). Increasing the reaction temperature to $180{ }^{\circ} \mathrm{C}$ shortened the reaction time from 24 to $3 \mathrm{~h}$ without significant changes in the yields (entry 2 ). In contrast, 4 was dominantly formed when the reaction was conducted under 
ambient light illumination (entry 3). Notably, 2 is thermally stable but photosensitive, and isolated 2 transforms predominantly to 4 ( $56 \%$ yield) upon photo-irradiation using a LED lamp ${ }^{8 \mathrm{c}}$ along with a retro-cycloaddition reaction to give $\mathrm{C}_{60}(22 \%$ yield $)$.

\section{Scheme 1}

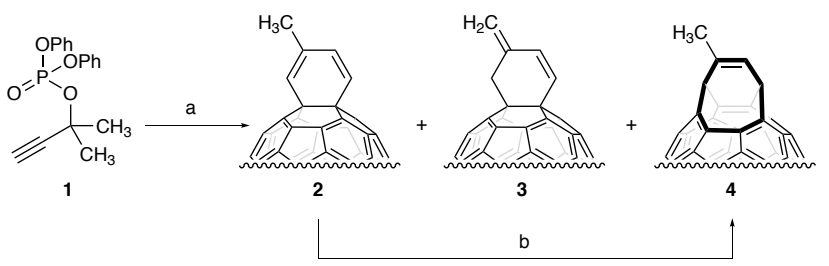

a) $\mathrm{C}_{60}, \mathrm{CuCl}, \mathbf{1 , 2}-\mathrm{DCB}$. Yields of 2, 3, and 4 are summarized in Table 1. b) $\mathrm{CS}_{2}, h v, 56 \%$ (4).

Table 1. CuCl-mediated reaction of $\mathrm{C}_{60}$ with $\mathrm{1}^{a}$

\begin{tabular}{|c|c|c|c|c|c|c|}
\hline entry & $\begin{array}{l}\text { temp. } \\
/ \stackrel{\circ}{ } \mathrm{C}\end{array}$ & $\begin{array}{l}\text { con- } \\
\text { dition }\end{array}$ & $\begin{array}{l}\text { tim } \\
\text { e / h }\end{array}$ & $\begin{array}{l}\% \\
\text { yield } \\
\text { of } \mathbf{2}^{b}\end{array}$ & $\begin{array}{l}\% \\
\text { yield } \\
\text { of } 3^{b}\end{array}$ & $\begin{array}{l}\% \\
\text { yield } \\
\text { of } 4^{b}\end{array}$ \\
\hline 1 & 110 & Dark & 24 & $\begin{array}{l}24 \\
(56)\end{array}$ & $9(21)$ & $5(12)$ \\
\hline 2 & 180 & Dark & 3 & $\begin{array}{l}24 \\
(26)\end{array}$ & $2(2)$ & Trace \\
\hline 3 & 180 & Light $^{c}$ & 4 & $-{ }^{d}$ & $-{ }^{d}$ & 35 \\
\hline
\end{tabular}

${ }^{a}$ Reactions were performed in 1,2-DCB under argon. ${ }^{b}$ The values in parentheses show conversion yields (conv. y.) based on the amount of $\mathrm{C}_{60}$ consumed. ${ }^{c}$ Reactions were performed under ambient light illumination. ${ }^{d}$ Not isolated owing to contaminating complex byproducts.

The molecular structures of 2, 3, and 4 were characterized using MALDI-TOF MS spectrometry and NMR spectroscopy, as well as absorption spectroscopy. The ${ }^{1} \mathrm{H}$ NMR chemical shifts and the spin-spin couplings of 2,3 , and 4 are depicted in Figure $\mathrm{S}_{40}$ in the Supporting Information. The ${ }^{1} \mathrm{H}$ NMR spectrum of 2 exhibited a doublet at $1.58 \mathrm{ppm}$, which corresponds to a methyl proton, and also three methine signals as multiplet, double doublet, and doublet signals at $\sim 5.54,5.76$, and $5.87 \mathrm{ppm}$, respectively, wherein, the observed small coupling constants are attributable to the allylic long-range spin-spin couplings. ${ }^{16}$ The observed NMR spectra agree well with the cyclohexadiene-annulated structure of $\mathbf{2}$. In contrast, the ${ }^{1} \mathrm{H}$ NMR spectrum of 4 exhibited similar chemical shifts but different coupling patterns as compared with that of $\mathbf{2}$, and the appearance of signals indicating one methyl proton at $1.66 \mathrm{ppm}$ as a doublet, and three methine signals at $5.65 \mathrm{ppm}$ as a singlet, at $5.79 \mathrm{ppm}$ as a doublet, and at $5.84 \mathrm{ppm}$ as a double quartet signals, respectively, is in agreement with the bisfulleroid structure of 4 . In stark contrast, the signal corresponding to a methyl proton was not found in the ${ }^{1} \mathrm{H}$ NMR spectrum of 3, and instead, a methylene proton signal at ca. 3.65 ppm as a multiplet, and two olefinic $\mathrm{CH}$ protons at $\sim 4.78$ and $\sim 4.85 \mathrm{ppm}$ as multiplets, and two additional olefinic $\mathrm{CH}$ protons at 6.31 and $6.52 \mathrm{ppm}$ as doublet signals, appeared respectively. The existence of a methylidene structure in 3 was also supported by the HMQC NMR spectrum, where the two methylene-proton signals at 4.78 and $4.85 \mathrm{ppm}$ correlate with the same carbon signal appearing at 115.26 ppm. The observed ${ }^{1} \mathrm{H}$ and ${ }^{13} \mathrm{C}$ chemical shifts of 2,3 , and 4 accord well with the ones calculated at the $\mathrm{GIAO}^{17}$ $\mathrm{B}_{3} \mathrm{LYP}^{18} / 6-31 \mathrm{G}(\mathrm{d})^{19}$ level of theory. These sound agreements also support the structures of $\mathbf{2}, 3$, and 4 . The molecular structure of $\mathbf{2}$ was also confirmed by X-ray crystallography, as shown in Figure 1. ${ }^{20}$

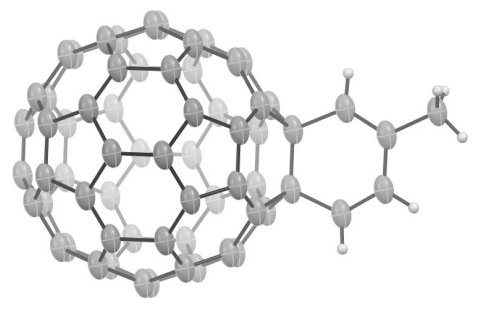

Figure 1. ORTEP drawing of 2 with thermal ellipsoids shown at the $30 \%$ probability level. Solvent molecules and disordered components are omitted for clarity.

A plausible reaction mechanism for the formation of $\mathbf{2}$ and 3 in the presented reaction is depicted in Scheme 2. It is likely that $\mathbf{1}$ is transformed first to the 1,3-dienyl phosphate 5 through 1,3-phosphryloxy migration, followed by proton elimination and subsequent protodemetalation. In related work, Gevorgyan et al. reported the transformation of propargylic phosphates into 1,3-dienyl phosphates under gold catalysts, ${ }^{21}$ and we propose that a similar transformation occurred in the presented reaction in the presence of $\mathrm{CuCl}$. The subsequent $[4+2]$ cycloaddition leads to the formation of the cyclohexene-annulated intermediate $\mathbf{6}$ in a pathway, which is similar to the reactions of $\mathrm{C}_{60}$ with propargylic esters reported previously. ${ }^{15 \mathrm{a}}$ In 6 , the ring flipping of the cyclohexene moiety causes a close contact between the oxygen of the phosphate group and the methylene proton of the opposite side as well as one of the methyl protons. Thus, we propose that subsequent intramolecular syn-elimination $^{22}$ of the phosphodiester through path A gives 2 or that through path B gives 3 , respectively. Such an elimination reaction does not occur during the thermal treatment of previously reported cyclohexene-annulated fullerene derivatives bearing carboxylate groups instead of phosphodiester groups. ${ }^{15 \mathrm{a}}$ In fact, the close proximity (3.1 $\AA$ ) between the oxygen atom of the phosphodiester group and the proton of the methyl group, which are at a distance that is close to the sum of their van der Waals radii (2.9 $\AA$ ) was found in the DFT-optimized structure of a ring-flipped conformer of 6, as shown in Figure 2. In addition, the proton of the methylene group is also located rather close to the oxygen atom with an interatomic distance of $3.9 \AA$. In this context, it is reasonable to conclude that the predominant formation of $\mathbf{2}$ over $\mathbf{4}$ is caused by the easier abstraction of the methylene proton, rather than the methyl proton. Subsequently, the transformation of 2 to 4 can be explained by invoking the well-established intramolecular [ 4 $+4]$ cycloaddition followed by retro- $[2+2+2]$ 
cycloaddition. ${ }^{3-7}$ Furthermore, DFT calculations showed that 2 and 3 are 10.35 and $11.25 \mathrm{kcal} \mathrm{mol}^{-1}$ higher in energy than 4, respectively. However, the results presented do not exclude the possibility that the $\mathrm{Cu}$-complex intermediate adds to $C_{60}$, followed by the dissociation of $\mathrm{Cu}$ to yield $\mathbf{6}^{23}$ In addition, copper may be coordinated ${ }^{24}$ to the phosphate group in intermediates such as 5 and $\mathbf{6}$.

Scheme 2. Plausible reaction pathways for the formation of 2 and $3 .{ }^{a}$
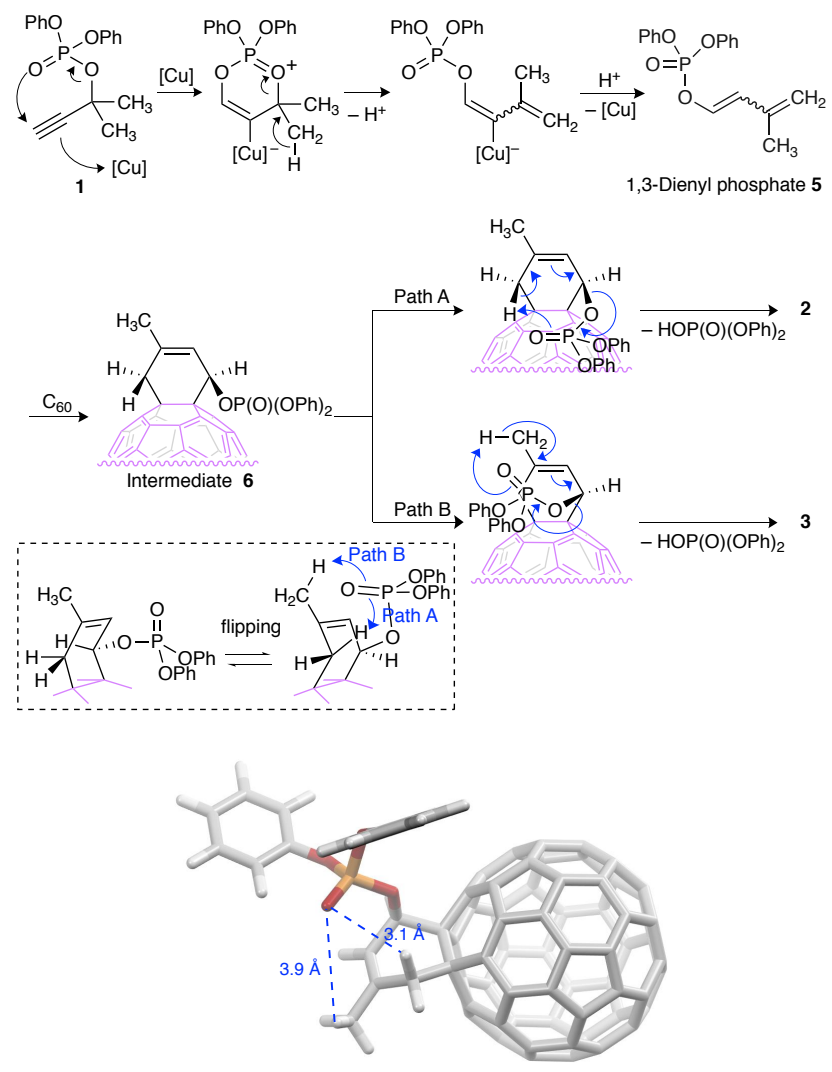

${ }^{a}$ Fullerene cage carbons are highlighted in purple. Inset shows the flipping motion of the cyclohexene moiety in the cyclohexene-annulated intermediate 6.

Figure 2. $B_{3} L Y P / 6-31 G(d, p)$-optimized structure of the ring-flipped conformer of 6 .

Scheme 3

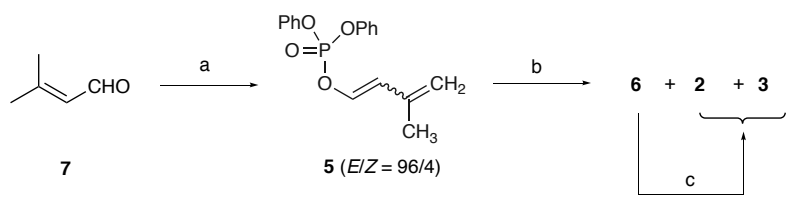

a) 1. $t$-BuOK, THF, N-Methylpyrrolidinone, $-78 \stackrel{\circ}{\circ} \mathrm{C} ; 2$. $\mathrm{ClP}(\mathrm{O})(\mathrm{OPh})_{2},-78^{\circ} \mathrm{C}$ to r.t., $\left.44 \%(5) . \mathrm{b}\right) \mathrm{C}_{60}$, toluene, $80{ }^{\circ} \mathrm{C}$, $12 \%(6), 12 \%(2), 3 \%(3)$. c) toluene, $80 \stackrel{\circ}{\circ}$, $69 \%(2), 9 \%(3)$.

To address the contribution of $\mathbf{5}$ and $\mathbf{6}$ for the formation of $\mathbf{2}$ and 3 in the $\mathrm{CuCl}$-mediated reaction of $\mathrm{C}_{60}$ with $\mathbf{1}$, we investigated the formation of $\mathbf{5}$ from $\mathbf{1}$ and the reactivity of $\mathrm{C}_{60}$ with 5 . Heating 1 at $110^{\circ} \mathrm{C}$ in the presence of $\mathrm{CuCl}$ for 3 $\mathrm{h}$ resulted in the formation of $\mathbf{5}$ in $5 \%$ yield $(E / Z=78 / 22)$, and the reaction proceeded with the complete consumption of 1 . On the other hand, heating 1 at $80{ }^{\circ} \mathrm{C}$ in the presence of $\mathrm{CuCl}$ for $3 \mathrm{~h}$ resulted in the formation of 5 in a trace amount (NMR yield, $<1 \%$ ) and the reaction proceeded with the incomplete consumption of $\mathbf{1}$, indicating that the rearrangement is incomplete at $8 \mathrm{o}{ }^{\circ} \mathrm{C}$. Alternatively, we synthesized 5 from 3-methyl-2-butenal (7) with diphenyl chlorophosphate in $44 \%$ yield as an $E$-enriched mixture $(E / Z=$ 96/4) by employing methods for the synthesis of related compounds (see Scheme 3 ). ${ }^{25}$ The reaction of $C_{60}$ with 5 did not proceed at ambient temperature but proceeded smoothly to afford 6 at $80{ }^{\circ} \mathrm{C}$. The gradual formation of $\mathbf{2}$ and 3 was also observed in the HPLC traces of the reaction mixture with an increase in the reaction time. Accordingly, 6 was obtained in $12 \%$ (conv. y. $25 \%$ based on the amount of $\mathrm{C}_{60}$ consumed) in addition to 2 (12\%; conv. y., $\left.29 \%\right)$ and 3 ( $3 \%$; conv. y., $7 \%$ ) after heating for 5 h. Furthermore, the thermolysis of the isolated 6 at $80{ }^{\circ} \mathrm{C}$ for $24 \mathrm{~h}$ resulted in its excellent conversion to 2 (69\%) and $3(9 \%)$.

The molecular structure of $\mathbf{6}$ was characterized using MALDI-TOF mass spectrometry and NMR spectroscopy, as well as absorption spectroscopy. While the parent peak corresponding to 6 in the MALDI-TOF mass spectrum was very weak, strong fragment peaks due to the loss of $\left[\mathrm{OP}(\mathrm{O})(\mathrm{OPh})_{2}\right]$ and $\left[\mathrm{OP}(\mathrm{O})(\mathrm{OPh})_{2}+\mathrm{H}\right]$ fragments in addition to those due to the loss of the whole addendum were observed, which suggest the facile elimination of the phosphodiester during mass spectrometry. The fragmentations were further confirmed with the MALDI-TOF/TOF mass spectra. Further, the ${ }^{1} \mathrm{H}$ NMR spectrum of 6 resembled that of a previously reported cyclohexene-annulated fullerene derivative bearing a carboxylate group instead of a phosphodiester group. ${ }^{15 \mathrm{a}}$ The ${ }^{13} \mathrm{C}$ NMR spectrum of $\mathbf{6}$ showed 47 peaks in the $\sim 120-160$ ppm range, which are attributable to the $\mathrm{sp}^{2}$ carbon atoms of the $\mathrm{C}_{60}$ skeleton and the addendum, and are consistent with the $C_{1}$ symmetric structure. We revisited the HPLC traces of the reaction mixtures of the $\mathrm{CuCl}$-mediated reactions of $\mathrm{C}_{60}$ with 1 at 110 and at $180{ }^{\circ} \mathrm{C}$ (i.e., entries $1-3$ in Table 1 ), and concluded that the formation of $\mathbf{6}$ was not detected possibly due to its thermal instability. On the other hand, when the reaction of $\mathrm{C}_{60}$ with 1 was conducted at $80{ }^{\circ} \mathrm{C}$ in the presence of $\mathrm{CuCl}, 2$ and 3 were formed scarcely. In the HPLC trace of the reaction mixture after heating for $22 \mathrm{~h}$, a small peak was found at $4.8 \mathrm{~min}$, the same retention time with that of 6 , in addition to the small peaks corresponding to 2 and 3 . In addition, the ${ }^{1} \mathrm{H}$ NMR spectrum of the reaction mixture suggested the formation of $\mathbf{5}$. Overall, these results point to the validity of the proposed reaction mechanism depicted in Scheme 2.

In summary, we have developed a new strategy for the synthesis of open-cage fullerenes by utilizing the coppermediated reaction cascades of $C_{60}$ with propargylic phosphate. A plausible reaction mechanism is proposed and the key intermediate species were also isolated and characterized. Additionally, we have found that 1,3-dienyl phosphate is useful for the preparation of open-cage fullerenes under mild conditions. We expect the presented reactions to 
have a broad scope in terms of applicability for the preparation of new open-cage and endohedral fullerenes. Further investigation to evaluate the generality and substrate scope of the presented method for preparing new opencage fullerenes remains ongoing, and relevant results will be reported as discoveries arise.

\section{ASSOCIATED CONTENT}

\section{Supporting Information}

The Supporting Information is available free of charge on the ACS Publications website.

Synthetic procedures, HPLC chromatograms, mass spectra, absorption spectra, X-ray crystallographic data, NMR spectra, and computational results (PDF)

Crystallographic data of $\mathbf{2}$ (CIF)

\section{AUTHOR INFORMATION}

\section{Corresponding Author}

*E-mail: myamada@u-gakugei.ac.jp

\section{Author Contributions}

The manuscript was written through contributions of all authors. / All authors have given approval to the final version of the manuscript.

\section{Notes}

The authors declare no competing financial interest.

\section{ACKNOWLEDGMENT}

This work was supported by TOBE MAKI Scholarship Foundation and the Noguchi Institute, and was partly supported by a Grant-in-Aid for Young Scientists (B) (16K1789o) from the Ministry of Education, Culture, Sports, Science, and Technology of Japan.

\section{REFERENCES}

(1) For selected reviews, see: (a) Rubin, Y. Chem. Eur. J. 1997, 3 , 1009-1016. (b) Komatsu, K.; Murata, Y. Chem. Lett. 2005, 34, 886891. (c) Iwamatsu, S.-i.; Murata, S. Synlett 2005, 14, 2117-2129. (d) Murata, M.; Murata, Y.; Komatsu, K. Chem. Commun. 2oo8, 46, 6083-6094. (e) Gan, L.; Yang, D.; Zhang, Q.; Huang, H. Adv. Mater. 2010, 22, 1498-1507. (f) Vougioukalakis, G. C.; Roubelakis, M. M.; Orfanopoulos, M. Chem. Soc. Rev. 2010, 39, 817-844. (g) Li, Y.; Gan, L.; Chem. Eur. J. 2017, 23, 10485-10490.

(2) (a) Murata, M.; Morinaka, Y.; Murata, Y.; Yoshikawa, O.; Sagawa, T.; Yoshikawa, S. Chem. Commun. 2011, 47, 7335-7337. (b) Chen, C.-P.; Lin, Y.-W.; Horng, J.-C.; Chuang, S.-C. Adv. Energy Mater. 2011, 1, 776-68o.

(3) (a) Arce, M.-J.; Viado, A.-L.; An, Y.-Z.; Khan, S. I.; Rubin, Y. J. Am. Chem. Soc. 1996, 118, 3775-3776. (b) Qian, W.; Rubin, Y. J. Org. Chem. 2002, 67, 7683-7687.

(4) (a) Hsiao, T.-Y.; Santhosh, K. C.; Liou, K.-F.; Cheng, C.-H. J. Am. Chem. Soc. 1998, 120, 12232-12236.

(5) (a) Murata, Y.; Kato, N.; Komatsu, K. J. Org. Chem. 2oo1, 66, 7235-7239. (b) Murata, Y.; Murata, M.; Komatsu, K. J. Org. Chem. 2oo1, 66, 8187-8191. (c) Murata, Y.; Murata, M.; Komatsu, K. Chem. Eur. J. 2003, 9, 1600-1609.

(6) Inoue, H.; Yamaguchi, H.; Suzuki, T.; Akasaka, T.; Murata, S. Synlett 2000, 8, 1178-1180.

(7) (a) Iwamatsu, S.-i.; Vijayalakshmi, P. S.; Hamajima, M.; Suresh, C. H.; Koga, N.; Suzuki, T.; Murata, S. Org. Lett. 2002, 4, 1217-1220. (b) Suresh, C. H.; Vijayalakshmi, P. S.; Iwamatsu, S.-i.; Murata, S.; Koga, N. J. Org. Chem. 2003, 68, 3522-3531.

(8) (a) Murata, Y.; Komatsu, K. Chem. Lett. 2oo1, 30, 896-897. (b) Inoue, H.; Yamaguchi, H.; Iwamatsu, S.-i.; Uozaki, T.; Suzuki, T.; Akasaka, T.; Nagase, S.; Murata, S. Tetrahedron Lett. 20o1, 42, 895897. (c) Hashikawa, Y.; Murata, Y. ChemPlusChem 2018, 83, 11791183.

(9) (a) Iwamatasu, S.-i.; Ono, F.; Murata, S. Chem. Lett. 2003, 32, 614-615. (b) Iwamatsu, S.-i.; Ono, F.; Murata, S. Chem. Communn. 2003, 1268-1269. (c) Iwamatsu, S.-i.; Kuwayama, T.; Kobayashi, K.; Nagase, S.; Murata, S. Synthesis 2004, 2962-2964.

(10) (a) Rubin, Y.; Jarrosson, T.; Wang, G.-W.; Bartberger, M. D.; Houk, K. N.; Schick, G.; Saunders, M.; Cross, R. J. Angew. Chem. Int. Ed. 2001, 40, 1543-1546. (b) Murata, Y.; Murata, M.; Komatsu, K. J. Am. Chem. Soc. 2003, 125, 7152-7153. (c) Iwamatsu, S.-i.; Uozaki, T.; Kobayashi, K.; Re, S.; Nagase, S.; Murata, S. J. Am. Chem. Soc. 2004, 126, 2668-2669. (d) Iwamatsu, S.-i.; Murata, S.; Andoh, Y.; Minoura, M.; Kobayashi, K.; Mizorogi, N.; Nagase, S. J. Org. Chem. 2005, 70, 4820-4825. (e) Iwamatsu, S.-i.; Stanisky, C. M.; Cross, R. J.; Saunders, M.; Mizorogi, N.; Nagase, S.; Murata, S. Angew. Chem. Int. Ed. 20o6, 45, 5337-5340. (f) Whitener Jr., K. E.; Cross, R. J.; Saunders, M.; Iwamatsu, S.-i.; Murata, S.; Mizorogi, N.; Nagase, S. J. Am. Chem. Soc. 2oo9, 131, 6338-6339. (g) Hashikawa, Y.; Murata, M.; Wakamiya, A.; Murata, Y. Org. Lett. 2014, 16, 2970-2973. (h) Krachmalnicoff, A.; Bounds, R.; Mamone, S.; Levitt, M. H.; Carravetta, M.; Whitby, R. J. Chem. Commun. 2015, 51, 4993-4996. (i) Xu, L.; Ren, H.; Liang, S.; Sun, J.; Liu, Y.; Gan, L. Chem. Eur. J. 2015, 21, 13539-13543. (j) Chen, C.-S.; Kuo, T.S.; Yeh, W.-Y. Chem. Eur. J. 2016, 22, 8773-8776.

(11) (a) Komatsu, K.; Murata, M.; Murata, Y. Science 2005, 307, 238240. (b) Murata, M.; Murata, Y.; Komatsu, K. J. Am. Chem. Soc. 2006, 128, 8024-8033.

(12) (a) Kurotobi, K.; Murata, Y. Science 2011, 333, 613-616. (b) Krachmalnicoff, A.; Levitt, M. H.; Whitby, R. J. Chem. Commun. 2014, 50, 13037-13040.

(13) Krachmalnicoff, A.; Bounds, R.; Mamone, S.; Alom, S.; Concistrè, M.; Meier, B.; Kouril, K.; Light, M. E.; Johnson, M. R.; Rols, S.; Horsewill, A. J.; Shugai, A.; Nagel, U.; Rõõm, T.; Carravetta, M.; Levitt, M. H.; Whitby, R. J. Nat. Chem. 2o16, 8, 953-957.

(14) Bloodworth, S.; Sitinova, G.; Alom, S.; Vidal, S.; Bacanu, G. R.; Elliot, S. J.; Light, M. E.; Herniman, J. M.; Langley, G. J.; Levitt, M. H.; Whitby, R. J. Angew. Chem. Int. Ed. 2019, 58, 5038-5043.

(15) (a) Yamada, M.; Ochi, R.; Yamamoto, Y.; Okada, S.; Maeda, Y. Org. Biomol. Chem. 2017, 15, 8499-8503. (b) Yamada, M.; Takizawa, M.; Nukatani, Y.; Suzuki, M.; Maeda, Y. J. Org. Chem. 2019, 84, 9025-9033.

(16) Prado, G.; Veiga, A. X.; Fernández-Nieto, F.; Paleo, M. R.; Sardina, F. J. Org. Lett. 2015, 17, 2054-2057.

(17) Wolinski, K.; Hinton, J. F.; Pulay, P. J. Am. Chem. Soc. 1990 112, 8251-826o.

(18) (a) Becke, A. D. Phys. Rev. A: At., Mol., Opt. Phys. 1988, 38 , 3098-310o. (b) Becke, A. D. J. Chem. Phys. 1993, 98, 5648-5652. (c) Lee, C. Yang, W.; Parr, R. G. Phys. Rev. B: Condens. Matter Mater. Phys. 1988, 37, 785-789.

(19) Hehre, W. J.; Ditchfield, R.; Pople, J. A. J. Chem. Phys. 1972, 56, 2257-2261.

(20) CCDC 1990838 contains the supplementary crystallographic data for this paper. These data can be obtained free of charge from The Cambridge Crystallographic Data Center.

(21) (a) Dudnik, A. S.; Schwier, T.; Gevorgyan, V. Org. Lett. 2oo8, 10, 1465-1468. (b) Dudnik, A. S.; Schwier, T.; Gevorgyan, V. Tetrahedron 2009, 65, 1859-1870. (c) Dudnik, A. S.; Schwier, T.; Gevorgyan, V. J. Organomet. Chem. 2oo9, 694, 482-485. (d) Shiroodi, R. K.; Dudnik, A. S.; Gevorgyan, V. J. Am. Chem. Soc. 2012, 134, 6928-6931. (e) Shiroodi, R. K.; Gevorgyan, V. Chem. Soc. Rev. 2013, 42, 4991-5001. 
(22) (a) Kurihara, T.; Miki, M.; Yoneda, R.; Harusawa, S. Chem. Pharm. Bull. 1986, 34, 2747-2753. (b) Krawczyk, E.; Owsianik, K.; Skowronska, A. Tetrahedron 2oo5, 61, 1449-1457.

(23) S. Reymond, J. Cossy, Chem. Rev. 2008, 108, 5359-5406.
(24) S. Sabiah, B. Varghese, N. N. Murthy, Chem. Commun. 2009, 5636-5638.

(25) Cahiez, G.; Habiak, V.; Gager, O. J. Org. Chem. 20o8, 73, 68716872 . 